\title{
Dispute Resolution approaches for public projects in the construction industry within Gauteng Province
}

\author{
Nazeem Ansary and Olanrewaju Balogun
}

\begin{abstract}
- this paper gives an understanding into the variables which affect upon the determination of dispute resolution strategies on a public projects in the construction industry in Gauteng Province of South Africa. The accompanying elements are utilized, for example, cost, speed, result, enforceability, protection and classification, open and reasonableness, control, adaptability inventive cures and connections. The dispute review board will be compared with alternative dispute resolution methods to demonstrate the differences and the impact it has on construction performance, primarily time, cost and quality. The Survey questionnaire were used to justify the relative importance of these factors in the selection of dispute resolution methods is examined and through one-on-one interviews, the efficiency of the current alternative dispute resolution methods operating in Gauteng construction industry is compared with the efficiency of the dispute review board. Concerns with respect to the utilization of DRB emerging from high costs, absence of confidence in the board's capacity to accomplish characteristics of non-partisanship and fairness in the determination of wide individuals and additionally the general state of mind of protection from change in the exceedingly ill-disposed culture of the development business will be talked about. Negotiation is as yet the favoured strategy for dispute resolution in construction industry Gauteng province.
\end{abstract}

Keywords-: Dispute review board, alternative dispute resolution, Gauteng construction industry

\section{Introduction}

Construction is an exceedingly complex activity coupled with vulnerabilities: efficient, money related, and physical consequences, and in addition scope varieties and documentation complexities [23]. Research of the past shows that amid the development procedure these dangers can prompt debate emerging between at least two of the gatherings engaged with the works [9]. In South Africa, 54\% of all construction projects and 560 million are postponed [5].The key prerequisites of any techniques for dispute resolution are they should be founded on equity and is reasonable and unprejudiced [9]. Construction law in South Africa is based the customary litigation, it depends on the foe framework comprising of a progression of articulations of certainties and contentions of law set forward by the gathering to be questioned and tested by the other party [19]. For other disputed techniques, for example, the Alternative Dispute Resolution (ADR) it is non-authoritative however when a composed understanding hosts been finished up between the two gatherings then it turns into an agreement which the two gatherings are obliged to consent.

The Dispute Review Board (DRB or DB) is a Dispute Avoidance Procedure method to settle various construction dispute claims [8]. Other techniques include voluntary negotiations between the parties; third party assisted negotiations such as mediation, conciliation and adjudication; and adversarial approaches such as arbitration or litigation [24]. The Gauteng construction industry is based more on relationships than most others and as a result dispute resolution using ADR methods, such as mediation allow flexibility in addressing technical issues and preservation of relationships as well as minimising adverse publicity[24].[20] However, sufficient attention should be directed to the dispute resolution clauses at the time of contract preparation and negotiation to avoid costly, time consuming as well as distracting and ineffective dispute resolution processes later on.[10].

This research aims to explore the importance of the factors which affect the dispute resolution Approached in Gauteng Construction industry when compared to the dispute review board as well as the efficiency of the current dispute resolution techniques in Construction industry in Gauteng.

\section{Conflict and Dispute}

Conceptually a conflict is a difference between two or more beliefs, ideas, or interests[4]. Based on the above definition conflict in construction may include dissatisfaction, disagreements over contract administrator's decisions, anger, hostility, and negative attitudinal propensities by parties [1].

\footnotetext{
Nazeem Ansary

University Johannesburg

South Africa

nansary@uj.ac.za

Olanrewaju Abdul Balogun

University Johannesburg

South Africa

lbalogun@uj.ac.za
} 


\section{A. Disputes- When conflicts are unresolved}

Dispute arises in a situation when a claim or assertion made by one party is rejected by another party and this rejection is not accepted [15]. A claim is an assertion of a right to money, and property, or a remedy and can be made under the contract itself, for breach of the contract, or for breach of a duty in common law [21].

Construction claims can be in the form of money and time claims by the main contractor against the project owner for extension of contract time and additional payment arising from a specified event in the contract [1]. The claim can be any application to the project management team pursuant to any relevant clause of the contract including any variation to payments, extension of time and or damages for any alleged breach of duty by the employer or employer's management team [15].

\section{Dispute Resolution Methods}

Dispute resolution is a very important task in construction because huge sums are invested in projects and stakeholders are eager to resolve disputes before they bring their projects to a halt and bankrupt them. At the project level, unresolved disputes can lead to programme delay, increased tension, and can damage long term business relationships as a result.

An alternative dispute resolution method, like mediation was developed for various reasons, but mostly because the traditional processes, for instance litigation, were seen to be less favourable for the following reasons: Cost - Attorneys, senior council and expert witnesses, all contribute to heavy costs being incurred by both parties; Time - long waiting time for court dates where cases were often postponed for on-site visits, calling for expert witnesses, etc.; Most magistrates or judges are not specialists in the field of construction; and The outcomes often cause more damage. [7]; [18] \&[18];[17].

The following are some of the ADR methods used in the construction industry, all having the common goal to resolve disputes voluntarily and initiated by the parties themselves: Agent resolution; Informal discussion; Negotiation; Mediation; Conciliation; The mini trial; Engineering expert assessment; Adjudication; Dispute Review Board; Partnering; and Dispute Resolution Advisor System [26]; [27] \& [27].

\subsubsection{Agent Resolution (expert resolution)}

Traditionally, in the South African context, agent resolution (usually the architect) was the first stage towards resolving differences and disputes. The resolution by this agent was final and binding unless disputed within an agreed period [22]; [7]. In terms of the Joint Building Contracts Committee (JBCC)[12], the principle agent shall give a decision, on request by the contractor, should there be any disagreement between the parties. Such a decision shall be final and binding unless timeously disputed. This clause has however been removed in the latest editions of JBCC Series 2000 [14]

\section{Adjudication}

Adjudication is an accelerated form of dispute resolution in which a neutral, impartial and independent third party deals with the dispute as an expert and not as an arbitrator, and whose determination is binding unless and until invalidated or overturned by an arbitration award [11]. The adjudicator shall not advise the parties or their representatives regarding any aspect of the agreement in respect of which he has been appointed other than in accordance with stated rules [13] The adjudicator's written determination of the dispute shall: Be delivered to the parties, and outline reasons for his decisions [13]. The decision is final and binding until and unless reversed by an arbitrator [14].

\section{Conciliation}

Conciliation involves a process of bringing disputing parties together in a forum to investigate the problem and assist the parties to formulate their own solutions; the conciliators may also be requested to formulate their own opinion. The parties decide who the conciliator will be. The conciliator should, however, be a person with good communication skills and relevant knowledge [16].

\section{Mediation}

Mediation means different things to different people, but in the construction industry, it usually denotes a procedure in which a neutral third party seeks to resolve a dispute between contracting parties through mutual agreement, by conducting an enquiry, similar to arbitration, but less formal and by giving a non-binding opinion. The parties represent themselves without calling in legal professionals. The mediator should know the details of the dispute and should give each party the opportunity to state their case. The mediator should decide on the best procedure, based on circumstances [6];[7];[11]; [18]\& [18]; [22]. Quantity surveyors often perform mediation tasks for clients or other parties, be it informal as a quantity surveyor, or a formal mediator by appointment. However, in terms of many contracts, JBCC, the parties shall agree on the appointment of a mediator and meet with the mediator in an effort to reach a settlement. If a settlement is reached, the mediator shall record such an agreement which shall become binding on the parties on the signing thereof [14].

\section{Arbitration}

In some countries, arbitration is a process provided for by an act of law, adopted by parties through mutual agreement, stipulating that they will submit any dispute that may arise between them to the impartial judgement of some 
third party of their choice and that the award by this impartial person will be final and binding. Arbitration is not a new process; in fact, it was known to the Romans, used by the Dutch and English in the days of colonial expansion and is currently widely used in the construction industry and further afield [7]. [2] suggests approaching an arbitrator rather than a lawyer. He further mentions the importance of securing a competent arbitrator, one well acquainted with the process of arbitration. In South Africa, arbitration is regulated by an act of parliament (South Africa 1969, Act 42). Arbitration is a more formal process than other disputeresolution processes mentioned earlier, but arbitration has many advantages. Some of these are: Expert knowledge of a selected arbitrator; Possible savings in legal representation costs Flexibility of the process; the decision is final and binding; Time and money are saved; and Arbitration is a private matter [2]\& [7]; [6];[7]; [18] \& [18]. Arbitration is sometimes also criticised as being only marginally quicker than litigation, especially where FIDIC documents are used [2].

\section{B. A Ten challenges affecting the performance of dispute resolution approaches}

Ten factors were used to test the performance of dispute resolution approaches namely, cost, speed, outcome, enforceability, privacy and confidentiality, open and fairness, control, flexibility, creative remedies and relationships as identified by [3].

Cost: The direct fees for the DRB ranging from $0.05 \%$ to $0.25 \%$ of the total construction cost. The fees are shared by both parties which mitigate the conflict of interest and perception of bias that all three DRB members will take one particular side. In mediation, conciliation and other current ADR methods operating in South Africa, there is only one member facilitating the negotiation for settlement between two parties.

Openness, Neutrality and Fairness: Neutrality, openness and fairness are the core values of the DRB. The board members must not have financial ties with any party. If there is a conflict of interest, it must be disclosed to all parties. The selection process for the DRB members is a consensus approach.

Speed: The DRB is established before the commencement of the project. It will involve the experts every early on the project and potential claims dispute may be identified before the issues surfaces as the conflict is resolved as they arise on site where as the current ADR methods in South Africa resolve disputes after the event has occurred. This solves the problem of delaying the time to sort out missing documentation and historical information to make an accurate determination. Additionally, the periodic site visit will improve the adversarial nature between conflicting parties when liability can be determined before the conflict turns into a dispute.

Outcome: The DRB has the flexibility of acting as an advisor as well as issue non-binding recommendations. The use of lawyers on the board is discouraged to avoid an adversarial climate however the question of liability is ruled upon by three members. This should encourage the parties to accept the board decisions especially if the contract language includes a provision for the admissibility of a DRB recommendation into any subsequent arbitration or legal proceeding.

Privacy and Confidentiality: The code of ethics for DRB stipulates that the DRB must keep all information arising from the DRB review and hearing confidential and since the dispute is resolved on site, no external party will know that an issue exists. This should preserve business relationships and prevent any unnecessary complexity which may arise from external parties after hearing about the dispute.

Enforceability: The DRB is non-binding however, the goal of the DRB is facilitate the conflicting parties to resolve their differences so that construction works can continue on site.

Preservation of Relationships: Both parties agree on the selection of the DRB members at the appointment of the board. This means that all parties are willing to cooperate with each other in good faith and trust the board's decision making abilities when a conflict arises. If the parties are unsatisfied with the decisions of the DRB, they are free to sort dispute resolution methods.

Flexibility: The DRB can act as a flexible panel acting as an advisor which will facilitate the negotiation process more than the current ADR methods which can only act as a neutral facilitator as with mediation or act to make a judgement of a technical issue as with expert determination. Litigation and arbitration are the least flexible methods as it is only interested in the issue which relate to a point of law and does not take into account of any other factors.

Creative Remedies: The DRB is a panel of three experts with different but relevant qualifications, skills and more than ten years of experience within the construction industry. The blend of qualifications and experience of the threeperson DRB can provide a powerful combination of decision-making abilities than one person trying to make a judge within their limits of understanding and experience which is the case with expert determination.

Degree of Control: As mentioned before, the DRB members are agreed upon by both parties and the board resolves issues on site. The board can also act as an advisory panel which is not possible with the current operation of ADR methods. These factors give both parties a feeling of being control of the outcome and processes involved to reach an agreement. 


\section{Methodology}

The entire process comprised of a pre-interview questionnaire, structured interview and a post interview questionnaire to examine the respondents 'perception of the DRB's conflict management mechanisms in comparison with other dispute resolution techniques. Questionnaire There were seventy survey questions asking the respondents to rank from the likert scale of 1 to 5 (1 for extremely unimportant and 5 for extremely important), whether they think the ten criteria factors are important in the comparison for dispute resolution methods. The population sample was restricted to the Gauteng construction industry. The research sample consisted of twenty three respondents which undertook both the structured interview and questionnaires. The research sample included: five architects, three engineers, three quantity surveyors, two development managers, three project managers, one project director, one owner, one site foreman and two construction managers. Fifteen of these participants had over ten years of experience in their respective field of work. Eighty percent of the respondents answered that the project size their company generally undertake is in excess of R10 million. The average number of disputes that each building professional had been involved in over the last five years was five which confirms that these respondents have had a reasonable level of experience.

\section{Data Analysis Tool}

\section{Structured Interview Analysis}

The structured interview has been analysed using the grounded theory 'approach, an example can be referred in [25].

\section{Questionnaire Survey data analysis}

To measure the performance of the conflict management mechanisms of the DRB in comparison with other dispute resolution methods a mathematical equation, Relative Importance Index (RPI) was used for the analysis of the quantitative data. Relative Performance Index To determine the performance of any dispute resolution method when compared with DRB on each criterion, the respondents'ratings are transformed in Relative Performance Index (RPI) for each criterion. RPI is computed using the following mathematical expression:

\section{$\mathrm{RPI}=\Sigma \mathrm{Wi} /(\mathrm{A} \times \mathrm{n})$}

Where $\Sigma \mathrm{Wi}$ is the total score assigned importance of a decision criterion by all the respondents;

$\mathrm{A}$ is the highest weight (5; and $\mathrm{n}$ is the number of respondents. The computed RPI are then ranked for each dispute resolution method on each criterion. The areas of comparative advantages of the DRB over dispute resolution method on each criterion were identified.

\section{Results}

\section{Analysis of Data from Pre-Interview Questionnaires}

The results of this section present the demographics of the respondents and the current climate of dispute resolution in the Construction Industry in Gauteng Province.

The results in Table 1.1 shown that $48.3 \%$ of the respondents held positions in a managerial capacity and $51.7 \%$ of the respondents held positions as a consultant in design, engineering and cost management. This demonstrates that all the respondents who participated in the research had the capacity to make decisions regarding dispute resolution in their organisation.

The results of this section present the demographics of the respondents and the current climate of dispute resolution in the Construction Industry in Gauteng Province.

The results in Table 1.1 shown that $48.3 \%$ of the respondents held positions in a managerial capacity and $51.7 \%$ of the respondents held positions as a consultant in design, engineering and cost management. This demonstrates that all the respondents who participated in the research had the capacity to make decisions regarding dispute resolution in their organisation.

\section{TABLE 1:1 PROFILE OF RESPONDENT.}

\begin{tabular}{|l|l|}
\hline \multicolumn{1}{|c|}{ Professional } & \multicolumn{1}{c|}{ Percentages } \\
\hline Architect & 20 \\
\hline Engineer & 15 \\
\hline Quantity Surveyor & 16 \\
\hline Project Manager & 19 \\
\hline Construction Manager & 11 \\
\hline Development Manager & 15 \\
\hline Site Foreman & 4 \\
\hline Total & 100 \\
\hline
\end{tabular}

The results in Table 1.2 indicates that $78 \%$ of the respondents were over thirty years old. $22 \%$ of the respondents were between the age group of 30-40 years old and $31 \%$ of the respondents were between $40-50$ years old. $25 \%$ of the respondents were between the ages 50-60 years and held positions in senior management and $24 \%$ of the respondents were between the ages of 25-30years. Different age groups of professional have a different perception towards conflict management due to the length of their life and work experience.

TABL1.2 AGE OF RESPONDENTS

\begin{tabular}{|l|l|l|}
\hline Items & Ages Range & Percentages \\
\hline 1 & $25-30$ & 26 \\
\hline 2 & $30-40$ & 31 \\
\hline 3 & $40-50$ & 25 \\
\hline 5 & $50-60$ & 18 \\
\hline Total & & 100 \\
\hline
\end{tabular}

The results in Table 1.3 , shows that $35 \%$ of the respondents had more than 20 -30years of experience within 
ISBN: 978-1-63248-139-9 doi: 10.15224/ 978-1-63248-139-9-56

the construction industry, $22 \%$ of the respondents had 10-20 years of experience, $14 \%$ of the respondents had more than 30 years of experience and $29 \%$ of the respondents had less than 10 positions. Senior managers focus on strategic views whilst middle managers focus on efficient project operation and younger managers bring creativity into the workplace.

TABLE 1.3 YEARS OF EXPERRIENCE IN CONSTRUCTION PROJECTS

\begin{tabular}{|c|l|l|}
\hline Items & Years of Experience & Percentages \\
\hline 1 & $0-10$ years & 29 \\
\hline 2 & $10-20$ & 22 \\
\hline 3 & $20-30$ & 35 \\
\hline 5 & 30 above & 14 \\
\hline Total & & 100 \\
\hline
\end{tabular}

The result in the Table1:4 of the size of the projects, indicates that $71 \%$ of the respondents worked in large corporations which usually undertook big project in access of more than R35 million. Usually, the larger projects have more complexity and risks associated than smaller projects and so are more likely to encounter disputes. Likewise on the Table 1:5 on the contractual disputes encountered during the past five year, shows that the $72 \%$ of the respondents encountered between one to three disputes during the past five years. Table 1:6 on the types of disputes shows that most common types of dispute encountered by the respondents were all related to money, in particular $37 \%$ of the disputes were related payment for variation, $17 \%$ of the disputes were related to quality of materials and $14 \%$ of the disputes were extensions of time. As indicated on Table 1:7 on commonly used dispute resolution methods the result on that table shows that negotiation was the most commonly used method for dispute resolution followed by mediation. Respondents preferred to negotiate at all times to resolve disputes. While on the last Table 1:8 on the overall satisfaction with the current dispute resolution approaches the results on that table indicates that the respondents were most satisfied when negotiation was used for dispute resolution. Through the interviews, respondents were most satisfied with the outcome of negotiation and emphasised the importance of excellent communication skills and the preservation of relationships in the construction industry in Gauteng Province of South Africa.

\section{Importance of the criteria for dispute resolution approaches}

Respondents were asked to rank on a 1-5 likert scale the perceived importance of the ten criteria in the selection of dispute resolution methods. Results from the Relative Importance Indices analysis are displayed in table 1.9.

The results on the Table 1.8 below indicate that the cost, with the highest ranking of 1 , was the most important criteria when considering the dispute resolution methods. The second most important factor in the dispute resolution methods are open and fairness, speed and outcome. Preservation of relationship and enforceability was the third most important factor when considering methods of dispute resolution. Degree of control ranked 7 and privacy and confidentiality ranked 8 . The ranking of this research demonstrates that respondents are primarily concerned with the tangible benefits of dispute resolution. However, preservation of relationships is crucial for the Gauteng construction industry. Flexibility scored a lower ranking of 9 and creative remedies scored the lowest ranking of 10 . This indicates that respondents are less concerned with how disputes are resolved but focus on the results of the outcome

TABL1.8 IMPORTANCE OF FACTORS AFFECTING DISPUTE RESOLUTION APPROACHES

\begin{tabular}{|l|l|l|l|}
\hline Items & Total Score & RII* & Ranks \\
\hline Cost & 101 & 1 & 1 \\
\hline Open and fairness & 97 & 0.921 & 2 \\
\hline Speed & 97 & 0.921 & 2 \\
\hline Privacy & 59 & 0.615 & 8 \\
\hline Outcome & 88 & 0.921 & 2 \\
\hline Enforceability & 81 & 0.76 & 8 \\
\hline Relationship & 78 & 0.827 & 5 \\
\hline Flexibility & 61 & 0.6 & 9 \\
\hline Creative remedies & 53 & 0.475 & 10 \\
\hline Control & 67 & 0.66 & 7 \\
\hline
\end{tabular}

*RII=Relative Importance Index

\section{Conclusion}

Negotiation is still the preferred method of dispute resolution in Gauteng. Cost achieved the highest ranking RII value of 1 indicating that it was the most important performance criteria when in the selection of dispute resolution methods. Other critically important factors are speed, outcome, open and fairness as well as relationships. Flexibility and creative remedies received the lowest ranking score of 9 and 10 in RII indicating that in the context of project management professionals are more interested in the immediate tangible outcome when selecting dispute resolution methods than long term intangible benefits such as improvement in the process of dispute resolution for future benefits. The spirit of cooperation is evident in the dispute review board but is inadequate to improve adversarial attitude between parties. Extensive training at the graduate level is needed in order to change the general attitude of the high level of resistance to change in construction industry Gauteng Province. The notion that things can't improvell and disputes is just part of the job in this industry hinders the potential for the construction industry in Gauteng Province of South Africa to develop in full capacity and compete at international level. Further research can be done in the field of organisational change and learning to improve the training in organisational leadership and conflict management in project management.

\section{References}

[1] Aibinu, A.A., Ofori, G. and Ling, F.Y.Y. (2008), Explaining Cooperative Behaviour in Building and Civil Engineering Projects 
ISBN: 978-1-63248-139-9 doi: 10.15224/ 978-1-63248-139-9-56

'Claims Process: Interactive Effects of Outcome Favourability and Procedural Fairness', Journal of Construction Engineering and Management, ASCE, September, pp. 681-683

[2] Binnington, C. 2005. Arbitration - a cost effective mechanism? Legal matters. Civil Engineering Contractor, 39(11), p. 49-50, September.

[3] Cheung, S.O., Suen, H.C.H. and Lam. T.I, (2002) Fundamentals of alternative dispute resolution processes in construction', Journal of Construction Engineering and Management, Vol. 128, No. 5, October, pp. 409-416.

[4] Collin, J., Langford, D., and Kennedy, P. (1996), _The relationship between construction procurement strategies and construction contract disputes', CIB W92, North meets South, Durban, South Africa.

[5] Dawson, B. (2007), Scope for Improvement: A survey of pressure points in Australian construction and infrastructure projects Blake Dawson Waldron Lawyers.

[6] Eilenberg, I. 2002. Dispute Resolution in Construction Management. Sydney: UNSW.

[7] Finsen, E. 2005. The building contract: A commentary on the JBCC Agreements. 2nd ed. Cape Town: Juta.

[8] Gerber, P. (2001), -Dispute avoidance proceduresll, International Construction Law Review, Vol, 18, Issue 1 pp122

[9] Goldfayl, G. (2004), Construction Contract administration, USNW Press, New South Wales.

[10] Gould, N. (2006), Establishing dispute boards: Selecting, nominating and appointing board members, Society of Construction Law, pp. 130.

[11] Hibberd, P. and Newman, P. 2001. ADR and Adjudication in Construction Disputes. Oxford: Blackwell Science.

[12] Joint Building Contracts Committee (JBCC). 2004. Principal building agreement. 4th ed. Houghton: Joint Building Contracts Committee Inc. (Series 2000 Code 2101), March, p. 30.

[13] Joint Building Contracts Committee (JBCC). 2005. Adjudication Rules: for use with the JBCC Principal Building Agreement and Nominated Selected Subcontract Agreement. Ed. 4.1, cl. 1.1 3.2, 6.07.0. Houghton: Joint Building Contracts Committee Inc. (Series 2000 Code 2019), March.

[14] Joint Building Contracts Committee (JBCC). 2007. Adjudication Rules: for use with the JBCC Principal Building Agreement \& Nominated /Selected Subcontract Agreement. 5th ed.1-7. Houghton: Joint Building Contracts Committee Inc. (Series 2000 Code 2101).July.1-7.p.30-31.

[15] Kumaraswamy, M. H. (1997). Conflicts, claims and disputes in construction. Engineering, Construction and Architectural Management,

4(2), 95-111

[16] Loots, P. 1991. Alternative methods of dispute resolution in the construction industry. SA Builder, p. 8-13, May.

[17] Mackie, K.J. 1991. A handbook of dispute resolution: ADR in action. London \& New York: Routledge and Sweet \& Maxwell.

[18] McKenzie, H.S. and McKenzie, S.D. 2009. The law of building and engineering contracts and arbitration. 5th Ed. South Africa: Juta.

[19] McGranaghan, P.J. (1992), Alternative dispute resolution and the U.K. industry, Science Department, Sourth Bank Polytechnic, U.K.

[20] Megens, P. (2005), Mediation in construction', Conference September 2005- The Development of the use of Mediation in Dispute Resolution: A Global View, Mallesons Stephen Jaques, Hong Kong.

[21] Powell-Smith, V. and Sims, J. (1989), Building contract claims, (2nd ed), BSP Professional Books, London, U.K.

[22] Quail, P. 1978. Die boukontrak. Pretoria: Boupublikasies.

[23] She, L.Y., Aibinu, A \& Johnson, L (2010),Cooperation in Project Alliancing: The Service Profit Chain Approach in Building Interorganisational Relationships in Proceedings of Building a Better World, CIB May 10-13th May, 2010

[24] Sprague, J. (2006), The Melbourne Construction Industry: Alternative Dispute Resolution, the University of Melbourne, Melbourne, pp. 1-20
[25] Strauss, A and Corbin, J. (1998), Basics of Qualitative Research: Techniques and Procedures for Developing Grounded Theory, Sage Publications, United Kingdom

[26] Tiruneh, G.G., Verster, J.J.P. and Kotzé, B.G. 2007. A study on the application of alternative dispute resolution (ADR) methods in South Africa. Proceedings of Paciffic Association of Quantity Surveyors (PAQS) 2007 Congress: Construction from a different perspective. Auckland, New Zealand, June.

[27] Verster, J.J.P., Ramabodu, M.S. and Van Zyl, C.H. 2010. Construction dispute resolution as seen by Quantity Surveyors and Construction Managers. Proceedings of the 7th International Cost Engineering Council World and 14th Pacific Association of Quantity Surveyors Congress. Singapore. 23-27 July.

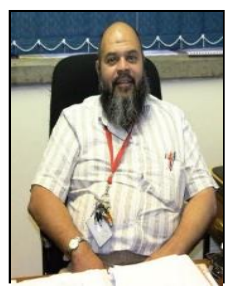

Nazeem Ansary (NHD, BTech QS, MCPM, PrQS PMAQS, MRICS, and FCIOB) holds a National Higher Diploma in Building Surveying and Bachelor's Degree in Quantity Surveying from Cape Peninsula University of Technology, South Africa and Tshwane University of Technology respectively. He received in 2010 his Master's Degree, Master of Construction Project Management from University of New South Wales, Australia. He is a Professional Quantity Surveyor and has many years of working experience in the construction industry and currently working as a senior lecturer and currently head of Department of Construction Management and Quantity Surveying at the University of Johannesburg South Africa. He has published several accredited articles in refereed journals and has presented papers in many international conferences all over the world. His main research interests are project management, construction management, dispute resolution, risk management in construction.

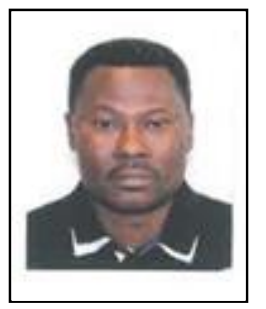

Olanrewaju Abdul Balogun (BSc Building) M.Tech, Dip, ASME) Holds a Bachelor's of Science in Building science,(Master Degree in Construction Management University of Johannesburg South Africa, Diploma in Project, Diploma in Blocking and Concreting and also a Member of American Society of Mechanical Engineers, Member Nigerian Institute of Building and has many years of working experience in the Construction Industry, Among orders are Telecommunication, Oil and Gas Industry. He is currently a lecturer and academic researcher at the Department of Construction Management and Quantity Surveying, University of Johannesburg. He has published extensively in various refereed conferences and has also presented papers in many international conferences all over the world. His main research interests are construction project management, construction management, and financial management in construction. 